\title{
Pelatihan Intermediate English Grammar di English Conversation Club MAN Kota Blitar dengan Menggunakan Metode Blended Learning
}

\author{
Dian Fadhilawati ${ }^{1}$, Bahrul Ulum ${ }^{2}$, Moh Mansur ${ }^{3}$ \\ Universitas Islam Balitar ${ }^{1,2,}$ MAN Kota Blitar ${ }^{3}$ \\ e-mail: dianfadhilawati@yahoo.com ${ }^{1}$, bahrul59@gmail.com ${ }^{2}$, mr.mohmansur@gmail.com $^{3}$
}

\begin{abstract}
Abstrak
Pelatihan Intermediate English Grammar di English Conversation Club (ECC) MAN Kota Blitar diadakan karena siswa ECC di MAN Kota Blitar memiliki penguasaan Intermediate English Grammar yang masih kurang. Berdasarkan hasil pre-test yang diadakan pada tanggal 14 Februari 2020, diperoleh hasil rata-rata yang tidak memuaskan yaitu 55.76. Grammar merupakan sub skill penting untuk membantu siswa dalam menulis atau berbicara dalam Bahasa Inggris secara tepat, oleh karena itu penulis merasa perlu membantu siswa tersebut agar memiliki penguasaan Intermediate English Grammar yang baik. Sebagai wujud pengabdian penulis kepada masyarakat, maka Penulis mengadakan Pelatihan Intemediate English Grammar dengan menggunakan Blended Learning yang dilaksanakan setiap hari Jumat mulai tanggal 14 Februari - 13 Maret 2020 di Aula English Corner MAN Kota Blitar, yang dilanjutkan dengan menggunakan Group WhatsApp (20 Maret-17 April 2020). Pelatihan ini diikuti oleh 50 siswa ECC MAN Kota Blitar dengan tertib. Setelah Siswa ECC MAN Kota Blitar mendapatkan pelatihan, penguasaan Grammar mereka meningkat menjadi 85.52. Dari hasil tersebut penulis berharap siswa ECC MAN Kota Blitar bisa mengaplikasikan ilmu yang mereka dapat melalui pelatihan tersebut untuk menulis atau berbicara Bahasa Inggris dengan menggunakan Grammar yang tepat
\end{abstract}

Kata Kunci: Pelatihan; Intermediate English Grammar; Blended Learning.

\begin{abstract}
Intermediate English Grammar Training at the English Conversation Club (ECC) MAN Kota Blitar was held because ECC students at MAN Kota Blitar had a lack of mastery of Intermediate English Grammar. The students' results of the pre-test on February 14, 2020 showed unsatisfactory result: 55.76. Grammar is an important sub skill to help students write or speak English appropriately, therefore the authors wanted to help them to have good mastery of Intermediate English Grammar. As a form of the author's dedication to the community, the authors conducted an Intermediate English Grammar Training using Blended Learning which is held every Friday by applying face to face meeting (14 February -13 March 2020) at the English Corner of MAN Kota Blitar, and continued by using WhatsApp Group (20 March-17 April 2020). Fifty students joined this training in an orderly manner. After ECC MAN Blitar students received the training, their Grammar mastery increased to 85.52. From that result, the writers hope that the students of ECC MAN Kota Blitar can apply the knowledge they got through the training to write or speak English using the appropriate Grammar.
\end{abstract}

Keywords: Intermediate English Grammar; Training; Blended Learning

\section{PENDAHULUAN}

Bahasa Inggris merupakan salah satu Bahasa Internasional yang harus dikuasai oleh siswa. Seperti kita tahu untuk komunikasi antarbangsa, Bahasa yang paling sering digunakan adalah Bahasa resmi PBB dalam hal ini salah satunya adalah Bahasa Inggris. (Kusuma, 2019) Mengungkapkan bahwa Bahasa Inggris merupakan salah satu Bahasa yang paling penting dan paling banyak digunakan di dunia seperti dipaki untuk seminar atau konferensi internasional, Pembacaan berita dunia, lirik music, diplomasi dan menjadi Bahasa dalam komunikasi bisnis maupun pemerintahan. Pembelajaran Bahasa Inggris sebagai Bahasa asing ataupun Bahasa kedua, ada beberapa elemen penting yang harus dipelajari oleh siswa diantaranya adalah tata Bahasa atau Grammar, kosa kata, dan pelafalan. Tata bahasa atau grammar selalu mempunyai peranan penting dalam komunikasi formal (Ismail, 2010). Lebih lanjut (Fadhilawati, 2019) mengatakan bahwa dengan memiliki pengetahuan Grammar yang baik siswa akan bisa menulis, dan berbicara Bahasa inggris dengan baik pula. Kalau ucapan ataupun tulisan kita secara grammatical benar maka komunikasi kita akan mudah dipahami oleh orang lain. 
Berdasarkan analisa awal yang penulis lakukan di MAN Kota Blitar yang teretak di Jalan Jati No 78 Blitar, Khususnya pada Siswa di English Conversation Club (ECC) MAN Kota Blitar masih kurang dalam penguasaan Intermediate Englih Grammar. Hal ini dibuktikan oleh hasil pre-test Intermediate Grammar dari 50 siswa ECC MAN Kota yang dilakukan pada tanggal 14 Februari 2020 masih jauh dari memuasakan. Pre Test Siswa mencakup 4 materi pokok yang memang dipelajari di SMA yaitu Passive voice, Conditional Sentences, Causative Verbs, dan Relative Pronouns. Pada Pre-test, rata-rata nilai siswa ECC adalah 55.76. Nilai tersebut masih dibawah pencapaian rata -rata minimal yang ditetapkan MAN Kota Blitar sebesar 75.00. Oleh karena itu, penulis sebagai dosen yang mengampu mata kuliah English Grammar di Universitas Islam Balitar tertarik untuk melakukan Pelatihan Intermediate English Grammar bagi siswa ECC di MAN Kota Blitar dengan menggunakan metode Blended Learning.

Metode Blended Learning adalah suatu metode pembelajaran yang mengkombinasikan 2 metode pembelajaran yaitu model face to face meeting atau pembelajaran tatap muka dengan pembelajaran yang menggunakan e-learning, dengan mengaplikasikan pembelajaran berbasis Blended Learning, diharapkan proses pembelajaran lebih menarik dan lebih flexible dimana siswa bisa mempelajari materi yang ditargetkan kapanpun dan dimanpun (Amal, 2019). Lebih lanjut (Isti'anah, 2017) mengungkapkan bahwa metode Blended learning merupakan suatu metode pembelajaran yang bisa membuat siswa mempelajari dan memahami Bahasa asing dengan mudah. Penggabungan antara pembelajaran online dan offiline diharapkan bisa menghasilkan pencapaian yang lebih maksimal daripada metode pembelajaran konvensional. Lebih lanjut (Isti'anah, 2017) melaporkan bahwa metode Blended learning efektif untuk meningkatkan pencapaian Grammar Bahasa Inggris mahasiswa Semester dua Prodi Sastra Inggris di Universitas Sanata Dharma. Selain itu, (Al Bataineh, Banikalef, \& Albashtawi, 2019) mengatakan bahwa Metode Blended learning mampu memberikan dampak yang positif pada pencapaian grammar siswa serta bisa meningkatkan motivasi siswa dalam pembelajaran Bahasa Inggris di Prodi Bahasa Inggris INU Yordania. Selain itu (Qindah, 2018) juga melaporkan bahwa metode Blended Learning memberikan dampak yang positif dalam pencapaian siswa dalam pembelajaran grammar siswa kelas 10 di salah satu sekolah negeri di Palestina didekat Ramallah.

Berdasarkan latar belakang diatas, Penulis tertarik untuk meningkatkan kemampuan intermediate English Grammar siswa ECC di MAN Kota Blitar dengan menggunakan metode Blended Learning. Jadi rumusan masalah dalam kegiatan ini adalah: Apakah kemampuan penguaasaan Intermediate English Grammar siswa di ECC MAN Kota Blitar akan meningkat setelah dilakukan pelatihan Intermediate English Grammar dengan menggunakan Metode Blended Learning?

Tujuan Kegiatan pengabdian masyarakat ini adalah untuk memberikan Pelatihan Intermediate English Grammar untuk meningkatkan penguasaan Grammar siswa ECC di MAN Kota Blitar pada level intermediate dengan menggunakan metode Blended Learning. Manfaat kegiatan ini adalah siswa ECC MAN Kota Blitar memiliki pemahaman yang lebih baik terhadap materi-materi Intermediate English Grammar yang harus mereka pelajari, sehingga diharapkan dengan mempunyai penguasaan Intermediate Grammar yang bagus mereka akan bisa berbicara maupun menulis dalam Bahasa Inggris secara tepat.

\section{METODE}

Metode Pengabdian Masyarakat yang diapikasikan oleh penulis adalah Metode Blended Learning dimana siswa mendapatkan pelatihan intermediate English Grammar secara face to face meeting dan melalui online learning Sebelum diliburkannya Sekolah, Karena Pandemi Covid 19, Penulis memberikan Pelatihan Intermediate English Grammar secara langsung datang ke sekolah tepatnya di ruang English Corner ECC Man Kota Blitar seperti yang dideskripsikan pada gambar 1 dibawah ini: 


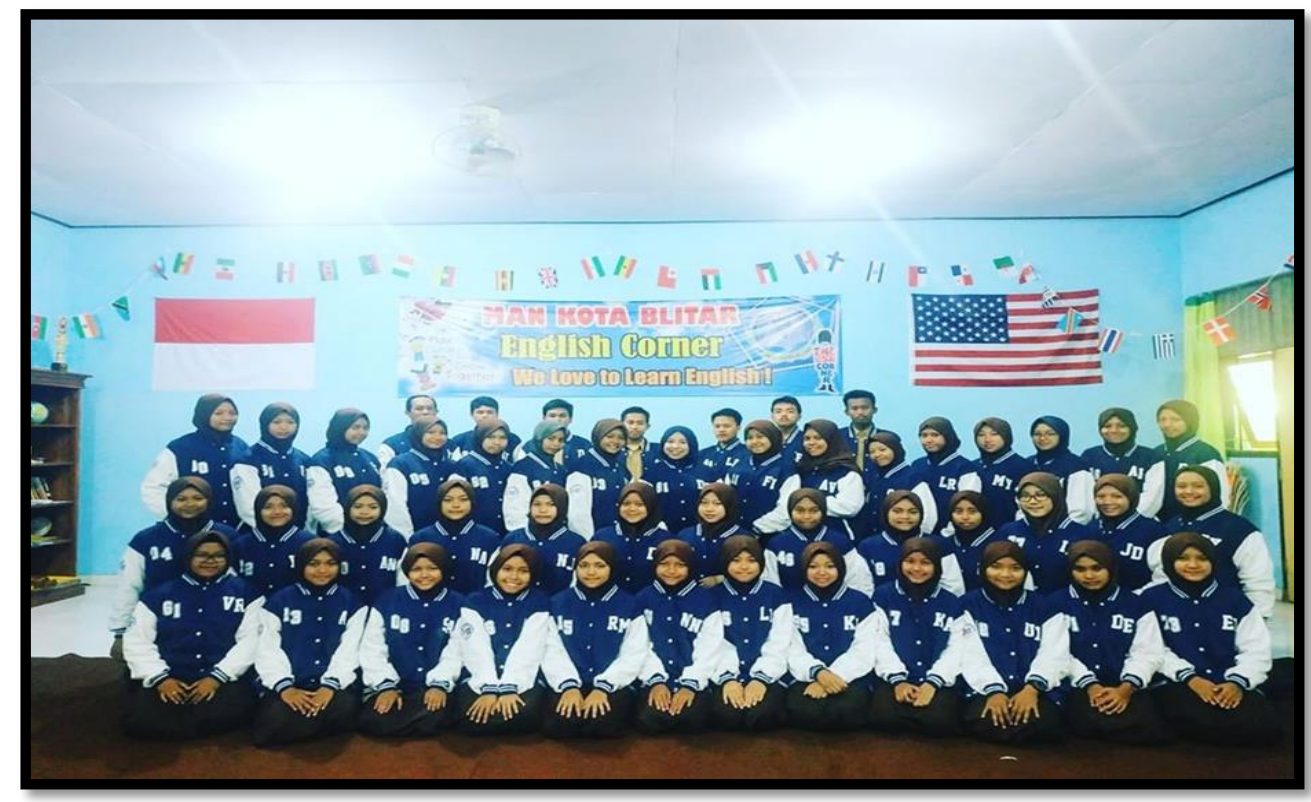

Gambar 1. Siswa ECC di English Corner MAN Kota Blitar

Metode Penyampaian materi yaitu dengan berceramah atau menerangkan secara langsung kepada siswa materi yang sudah ditargetkan dan dijadwalkan dalam setiap meetingnya. Pada saat Penyampaian materi penulis mengunakan Papan tulis dengan boardmarker berwarna untuk memotivasi siswa agar tidak mengantuk dan semangat dalam mengikuti pelatihan. Selain itu Penulis juga menggunakan media berupa LCD dan laptop untuk memutarkan materi berupa video atau film yang berhubungan dengan topik yang kita bahas.

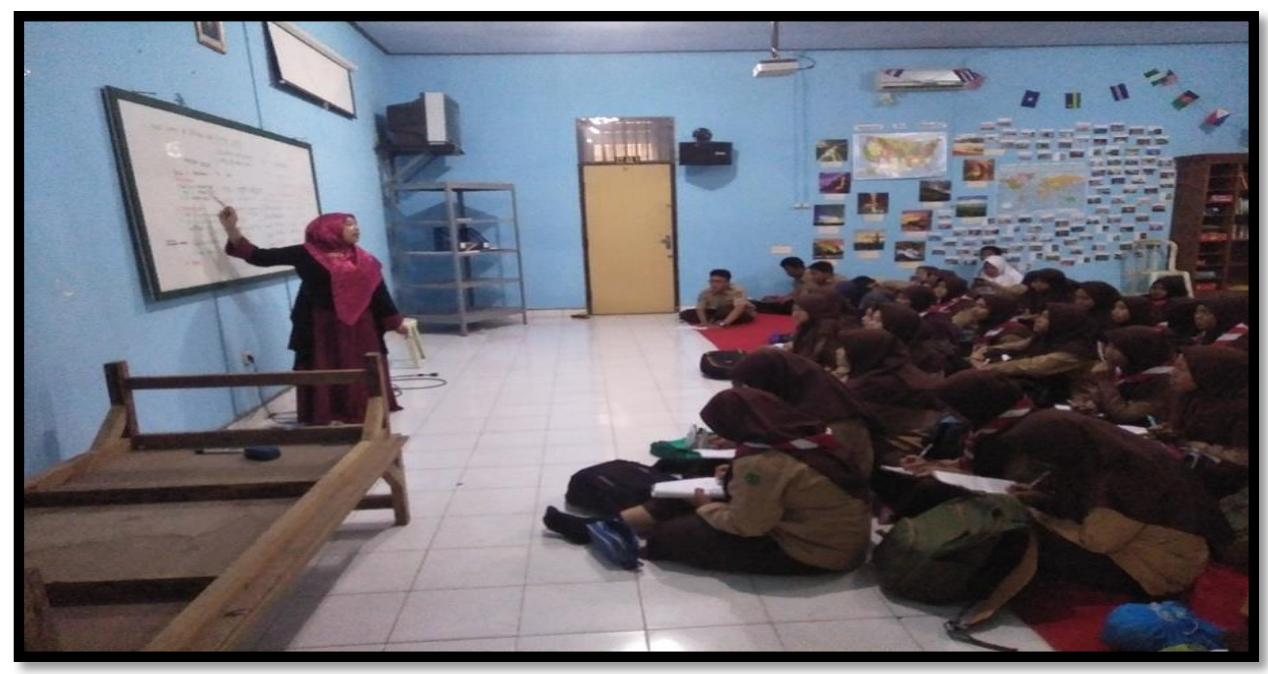

Gambar 2. Pembelajaran Grammar Melalui Face to face Meeting

Tetapi sejak 16 Maret 2020 Sekolah MAN Kota Blitar Melakukan Learning and Work From Home sehingga semua aktivitas pembelajaran maupun ekstrakulikuler termasuk dalam hal ini ECC dilakukan secarang daring atau online, Dalam hal ini penulis melanjutkan pelatihan Intermediate English Grammar secara online dengan menggunakan aplikasi yang memang tidak memberatkan siswa yaitu WhatsApp. Disini kami menggunakan Group WhatsAPP dengan nama ECC Next Generation yang berfungsi sebagai ajang atau wadah untuk sharing materi dan komunikasi sesama anggota maupun pelatih. Selain menggunakam metode ceramah pelatih juga menggunakan metode diskusi, untuk memecahkan masalah yang berkaitan dengan Intermediate English Grammar dikelas secara langsung 
maupun melalui chat WhatsApp Group. Berikut adalah Gambar nama group WhatsApp Untuk Pelatihan Sekaligus tujuan dari group WhatsApp kita.

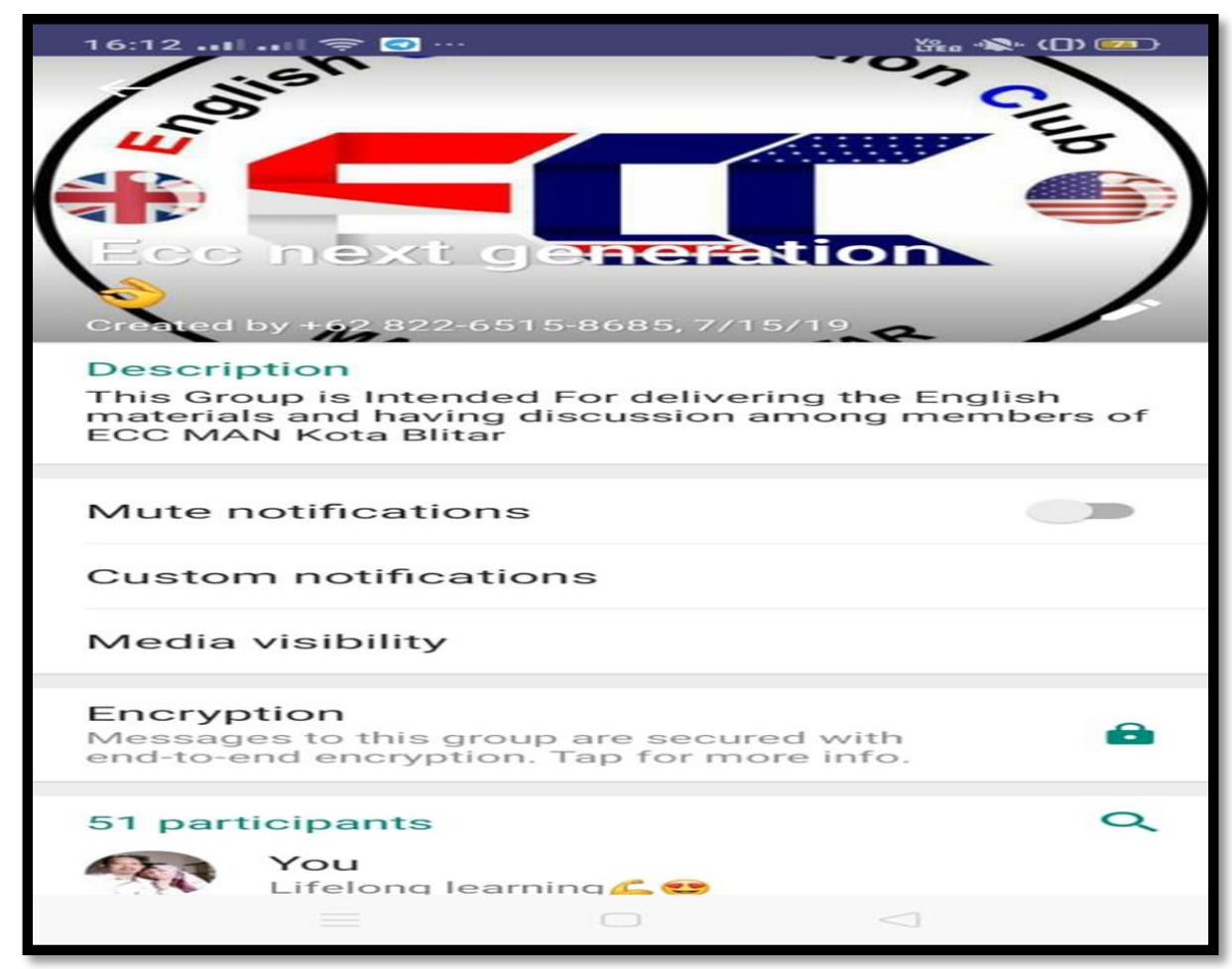

Gambar 3. Group WhatsAPP Pelatihan Intermediate English Grammar

Ada beberapa alasan mengapa pengabdi memilih WhatsAPP sebagai sarana pembelajaran, hal ini sesuai dengan (Amal, 2019) yang mengungkapkan bahwa Aplikasi Whatsapp adalah salah satu aplikasi yang bisa menjembatani komunikasi banyak orang baik secara audio maupun video yang memiliki kemapuan chat yang sangat baik bila dibandingkan dengan aplikasi chating sosial media yang lain sepertinya halnya Yahoo Massanger, BBM, ataupun FB Massanger. Lebih lanjut lagi (Amal, 2019) mengemukakan beberapa keunggulan dari aplikasi WhatsApp antara lain sebagai berikut: 1) Aplikasi Whatsapp merupakan satu aplikasi yang banyak digunakan oleh siswa dalam hal ini pengguna aplikasi Whatsapp sudah melenbihi 1 Miyar orang di dunia, 2) Aplikasi WhatsApp mudah untuk di instal dalam Handphone , 3) Data Penginstalan Aplikasi WhatsAapp kecil, 4) Aplikasi WhatsAapp bisa digunakan untuk membuat group, 5) Kecepatan chating aplikasi WhatsApp sangat bagus, 6) Aplikasi WhatsApp bisa dimanfaatkan untuk mengirimkan gambar, Video, Pesan suara, Voice note, link dan lain -lain, 7) Aplikasi WhatsAPP bisa kita manfaatkan untuk mengetik dengan menggunakan huruf miring, tebal maupun bergaris bawah, 8) Dalam aplikasi WhatsApp tersedia tanda untuk melihat apakah pesan kita sudah diterima atau belum.

Selanjutnya siswa mendapatkan materi baik secara face to face meeting maupun secara online melalui aplikasi WhatsApp langkah selanjutnya siswa mengerjakan latihan-latihan grammar yang sudah disediakan oleh pengabdi baik di dalam modul maupun dalam aplikasi pembelajaran online Yaitu Quizizz. Quizizz merupakan salah satu aplikasi yang sangat menarik berbasis game untuk pembelajaran. Aplikasi ini bisa meningkatkan perhatian, kreativitas, dan ketertarikan siswa dalam pembelajaran yang bisa diakses menggunakan SmartPhone atau laptop masing masing siswa (Dewi, Myartawan, Swari, \& Sugihartini, 2020). (Pitoyo, Sumardi, \& Asib, 2019) melaporkan bahwa aplikasi quizizz bisa membantu untuk mengurangi tingkat kecemasan siswa dan sangat bagus digunakan untuk ujian.Lebih lanjut, (Amalia, 2020) mengungkapakan bahwa aplikasi quizizz bisa menciptakan iklim kompetensi didalam kelas dan media ini sangat bagus untuk sarana pembelajaran dibandingkan media tradisional. Berikut contoh Latihan soal Grammar melalui aplikasi Quizizz yang pengabdi buat: 


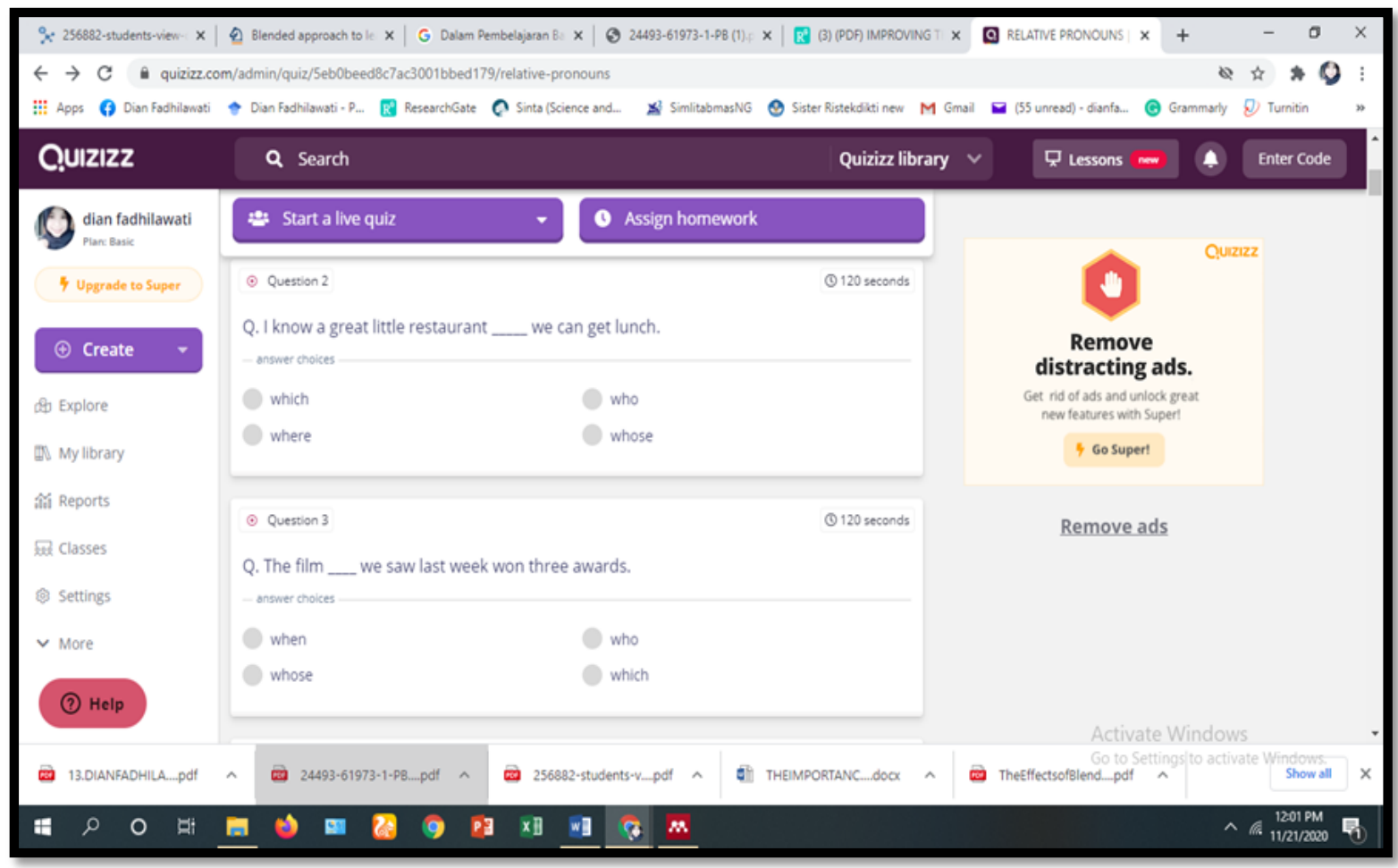

Gambar 4.latihan Soal Grammar Dengan Memggunakan Aplikasi Quizizz

Setelah pemberian materi selesai, diakhir sesi tepatnya Pada tanggal 17 April 2020, Penulis mengadakan Post-test untuk melihat sejauh mana peningkatan penguasaan Intermediate English Grammar siswa ECC MAN Kota Blitar setelah diadakannya pelatihan tersebut.

Pelatihan Intermediate English Grammar ini telah dilaksanakan oleh penulis setiap hari Jumat di English Corner MAN Kota Blitar (14 Februari - 13 Maret 2020) yang dilanjutkan dengan menggunakan Group WhatsApp (20 Maret-17 April 2020). Pelatihan ini diikuti oleh 50 siswa ECC MAN Kota Blitar dengan tertib. Berikut adalah waktu dan materi Pelatihan Intermediate English Grammar untuk setiap meetingnya:

Tabel 1. Jadwal dan Materi Pelatihan

\begin{tabular}{cll}
\hline Meeting & \multicolumn{1}{c}{ Tanggal Pelaksanaan } & \multicolumn{1}{c}{ Materi } \\
\hline $\mathbf{1}$ & Jumat, 14 Februari 2020 & $\begin{array}{l}\text { Pre- Test Intermediate English } \\
\text { Grammar }\end{array}$ \\
\hline $\mathbf{2}$ & Jumat, 21 Februari 2020 & Passive Voices sesi 1 \\
\hline $\mathbf{3}$ & Jumat, 28 Februari 2020 & Passive Voices sesi 2 \\
\hline $\mathbf{4}$ & Jumat, 6 Maret 2020 & Conditional Sentences (Nominal) \\
\hline $\mathbf{5}$ & Jumat, 13 Maret 2020 & Conditional sentences (Verbal) \\
\hline $\mathbf{6}$ & Jumat, 20 Maret 20120 & $\begin{array}{l}\text { Causative Verbs (let, Make, have + } \\
\text { O person +V1) }\end{array}$ \\
\hline $\mathbf{7}$ & Jumat, 27 Maret 2020 & $\begin{array}{l}\text { Causative Verbs (get, force, allow, } \\
\text { ask+ O person +to V1) }\end{array}$ \\
\hline $\mathbf{8}$ & Jumat, 3 April 2020 & $\begin{array}{l}\text { Relative Pronouns (Who, Whom, } \\
\text { Whose, Which, That, When, } \\
\text { Where) }\end{array}$ \\
& & $\begin{array}{l}\text { Post Test Intermediate English } \\
\text { Grammar }\end{array}$ \\
\hline $\mathbf{9}$ & Jumat, 17 April 2020 &
\end{tabular}




\section{HASIL DAN PEMBAHASAN}

\section{Hasil Penguasaan Intermediate English Grammar Setelah Dilaksanakan Pelatihan}

Hasil Pelatihan dari tanggal 14 Februari - 17 April 2020, Siswa ECC di MAN Kota Blitar mempunyai pengetahuan intermediate English Grammar yang sangat baik ini terbukti dari hasil petama pre-test yang diadakan pada tanggal 14 Februari 2020, nilai Siswa ECC rata rata grammar mereka masih sangat kurang (55.76). Nilai rata rata tersebut masih jauh dibawah minimal pencapaian kompetensi yang seharusnya yaitu (75.00). setelah melikuti Pelatihan Intermediate English Grammar yang diadakan penulis, Siswa di ECC MAN Kota Blitar, nilai rata-ratanya meningkat menjadi 85.52 Untuk hasil peningkatan pencapaian Grammar siswa ECC Man Kota Blitar bisa dilihat dalam figure dibawah ini:

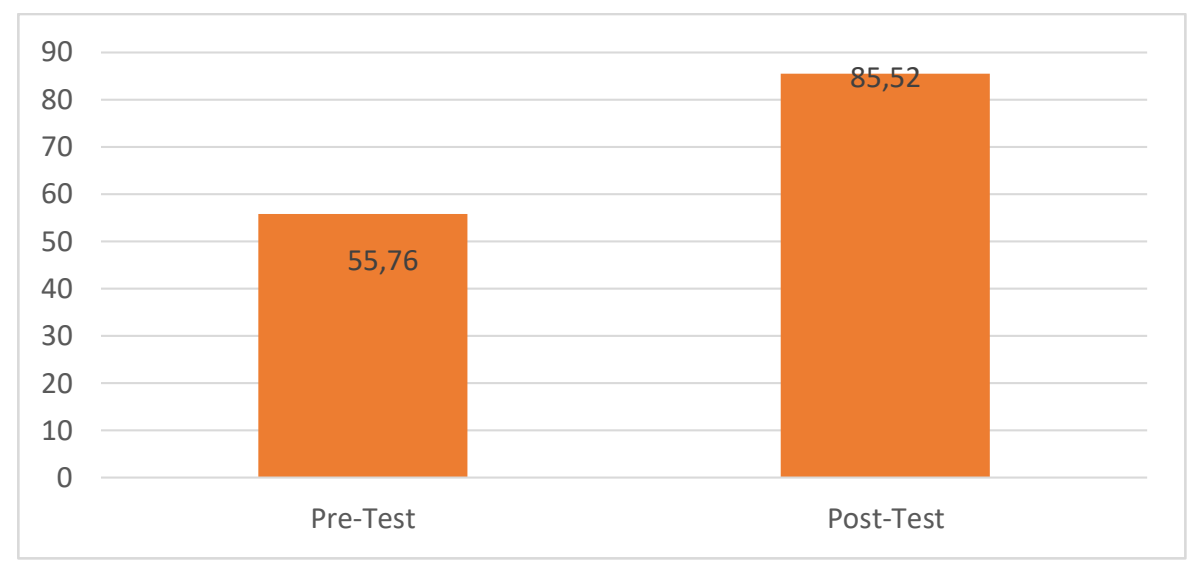

Gambar 5. Hasil Penguasaan Intermediate English Grammar Siswa ECC MAN Kota Blitar

\section{Pembahasan}

Mengacu pada pemaparan hasil diatas, kita bisa menyimpulkan bahwa Kemampuan Pemahaman Grammar siswa di ECC MAN Kota Blitar meningkat setelah diadakannya pelatihan intermediate English Grammar dengan menggunakan metode Blended Learning. Hal ini dibuktikan dari peningkatan hasil pencapaian yang cukup meningkat dari pre-test- yang diadakan pada tanggal 2 Agustus 2019 (55.76) menjadi 85.52 pada post-test yang diadakan pada tanggal 17 April 2020. Hasil tersebut mendukung hasil penelitian dari (Al Bataineh et al., 2019) yang melaporkan bahwa metode blended learning efektif untuk meningkatkan pembelajaran grammar siswa, selain itu juga juga senada dengan(Isti'anah, 2017) yang membuktikan bahwa penggunaan metode Blended Learning mampu memberikan hasil yang baik dalam proses pembelajaran grammar dibandingkan dengan metode konvensional. Lebih lanjut hasil pengabdian ini juga selaras dengan (Qindah, 2018) yang mengungkapkan bahwa metode Blended learning mampu memberikan dampak yang positif pada Pecapaian pembelajaran Grammar siswa.

\section{SIMPULAN}

Berdasarkan hasil yang telah dipresentasikan di atas, bisa disimpulkan bahwa pelaksanaan pelatihan Intermediate English Grammar bagi siswa English Conversation Club (ECC) di MAN Kota Blitar dengan mnggunakan metode Blended Laerning telah meningkatkan penguasaan Intermediate English Grammar siswa ECC di MAN Kota Blitar dengan hasil yang sangat memuaskan.

Dari hasil tersebut, penulis menyarankan agar siswa di ECC MAN kota Blitar bisa mengaplikasikan ilmu yang sudah diberikan pelatih untuk menulis Bahasa Inggris atau berbicara Bahasa Inggris dengan grammar yang tepat. Lebih lanjut, penulis berharap agar pelatihan ini bisa diteruskan di kemudian hari sebagai follow up dari program yang sudah dilaksanakan sebelumya dengan materi-materi English Grammar yang lain. 


\section{UCAPAN TERIMA KASIH}

Tim pengabdi menyampaikan apresiasi yang setinggi-tingginya kepada Lembaga Pengabdian Pada Masyarakat Universitas Isalm Balitar yang telah memberikan dukungan dana untuk kegiatan pengabdian kepada Masyarakat ini, sehingga semua program yang direncanakan bisa berjalan dengan lancar dari awal sampai akhir seperti yang direncanakan. Pengabdi juga memberikan apresiasi yang setinggi-tinnginya kepada pihak mitra dalam hal ini adalah MAN Kota Blitar yang telah memberikan ijin dan menyambut baik atas pelaksanaan program pelatihan Intermediate English Grammar dengan menggunakan Blended Learning di ECC MAN Kota Blitar.

\section{DAFTAR REFERENSI}

Al Bataineh, K. B., Banikalef, A. A. A., \& Albashtawi, A. H. (2019). The Effect of Blended Learning on EFL Students' Grammar Performance and Attitudes: An Investigation of Moodle. Arab World English Journal, 10(1), 324-334. https://doi.org/https://dx.doi.org/10.24093/awej/vol10no1.27

Amal, B. K. (2019). Pembelajaran Blended Learning Melalui Whatsapp Group (Wag). Prosiding Seminar Nasional Fakultas IImu Sosial Universitas Negeri Medan, 3, 700-702.

Amalia, D. F. (2020). Quizizz Website as an Online Assessment for English Teaching and Learning: Students' Perspectives. Jo-ELT (Journal of English Language Teaching) Fakultas Pendidikan Bahasa \& Seni Prodi Pendidikan Bahasa Inggris IKIP, 7(1), 1. https://doi.org/10.33394/jo-elt.v7i1.2638

Dewi, K. S., Myartawan, I. P. N. W., Swari, N. K. T. A., \& Sugihartini, N. (2020). Quizizz Effect on Students' Grammar Mastery in Higher Efl Classroom Based Mobile Assisted Language Learning (Mall). LEJU, 3(1), 15-24.

Fadhilawati, D. (2019). Improving the Students' Grammar Achievement on Conditional Sentences by Using Memrise. Langlit An International Per-Reviewed Open Access Journal, 5(4), 83-95.

Ismail, S. A. A. (2010). ESP Students' Views Of ESL Grammar Learning. Gema Online Journal of Language Studies, 10(3). Retrieved from http://ejournal.ukm.my/gema/article/view/83

Isti' anah, A. (2017). The Effect of Blended Learning to The Students' Achievement in Grammar Class. Indonesian Journal of English Education, 4(1), 16-30. https://doi.org/10.15408/ijee.v4i1.5697.IJEE

Kusuma, C. S. D. (2019). Integrasi bahasa Inggris dalam Proses Pembelajaran. Efisiensi - Kajian IImu Administrasi, 15(2), 43-50. https://doi.org/10.21831/efisiensi.v15i2.24493

Pitoyo, M. D., Sumardi, S., \& Asib, A. (2019). Gamification based assessment: A Test Anxiety Reduction through Game Elements in Quizizz Platform. International Online Journal of Education and Teaching (IOJET), 6(3), 456-471. Retrieved from http://iojet.org/index.php/IOJET/article/view/626

Qindah, S. (2018). The effects of blended learning on the intrinsic motivation of Thai EFL students. The Eurasia Proceedings of Educational \&Social Sciences (EPESS), 10, 11-22. 